\title{
Concurso público: reflexões acerca do dever de convocação pessoal dos candidatos
}

\author{
Public service exams: reflecitons on the participants personal convocation \\ obligation
}

\author{
Igor Silva de Menezes ${ }^{1}$
}

\section{Resumo}

Este artigo analisa pragmaticamente um aspecto que envolve princípios constitucionais dirigidos à Administração Pública e sua relação e aplicabilidade à garantia constitucional dos concursos públicos. A reflexão parte do problema que envolve o limite da discricionariedade do método adotado para a convocação dos candidatos a concurso público ante o princípio da acessibilidade ao cargo público e seus correlatos, quais sejam: publicidade, isonomia e impessoalidade. A discussão propõe metodologicamente comportamentos indispensáveis à tutela dos valores protegidos por esses princípios, a partir do raciocínio problemático e da teoria principiológica de Humberto Ávila, a fim de examinar os contornos da competência Judicial em controlar esses atos administrativos. Pretende-se contribuir com a jurisprudência na proposição de regras que condicionam uma Administração democrática e eficiente no trato desse assunto tão carente de disciplina jurídica que é o Concurso Público. $O$ objetivo do trabalho, em síntese, é a análise crítica dos principais argumentos que militam a favor e contra o dever de convocação pessoal do candidato em certames públicos.

Palavras-Chave: Concurso Público;Convocação pessoal; Controle Judicial da Administração.

\section{Abstract}

This article analysis pragmatically one aspect that envolves constitutional principles adressed to Public Administration and its relation and aplicability to contitucional guarantees of Public service exams. The reflection starts on the problem that envolves the limit of discricionality of the adopted method to the convocation of candidates of public service exams when confronted to the acessibility to public service principle and its similars: publicity, isonomy and impessoality. The discution metodologically proposes necessary behaviors to the guarantee of the values protected by this principles, starting from the problematic thought and the Humberto Ávila principiological theory, aiming to examinate the judicial attribution in controlling the administration acts. Intends to contribute with the jurisprudence on the proposition of rule that condition a democratic and efficient Administration

1 O autor é especialista em Direito Público (UNIG), Mestrando em Direito(UCAM), advogado, procurador do Município de Mesquita, Professor Universitário nos níveis de gradução e pós-graduação no RJ. 
on this matter that is so lacking of judical disciplin that is public service exams. The work objective, in summary, is to critically analyse of the main arguments in favor and against the obligation of personal convocation to the candidates in public exams.

Keywords: Public Exams; Personal convocation; Judicial Administration control.

\section{Introdução}

O presente trabalho teve como objeto de investigação os principais argumentos que embatem na discussão acerca da existência de um dever de convocação pessoal do candidato em certames públicos, bem como a reflexão sobre o controle judicial dos atos da Administração na escolha dos métodos e critérios utilizados discricionariamente em certames públicos.

Esse estudo se propõe a refletir sobre os contornos dos valores protegidos pelos princípios da razoabilidade, publicidade, isonomia e impessoalidade, e os comportamentos indispensáveis à concretização desses valores no processo de convocação de candidatos aprovados em concursos públicos, discutindo a eventual indispensabilidade do dever de convocação pessoal do candidato.

Embora o tema acessibilidade aos cargos públicos enseje inúmeras demandas judiciais, resta evidente a necessidade de um marco regulatório que discipline os concursos públicos. O que causa perplexidade é a inércia aparentemente proposital do legislativo em normatizar por lei esse, que se constitui como um dos direitos fundamentais do cidadão brasileiro, o direito de acesso a cargos e empregos públicos.

A carência legislativa que confira maior segurança jurídica aos candidatos, e que discipline as relações jurídicas e os procedimentos do principal mecanismo de investidura nos cargos e empregos públicos no Brasil, o concurso público, tem deslocado grande parcela da função normativa ao Judiciário, que amplia os contornos regulatórios naturais da função aplicadora do Direito em razão da ausência de texto legal específico.

Exsurge, nesse contexto, o controle judicial da Administração Pública, notadamente no que toca o instituto do concurso público, pela necessidade de verificação de compatibilidade horizontal e vertical do procedimento que compõe a principal etapa de provimento de cargos públicos efetivos. 
Como conseqüência da ausência de regulamentação, a par do novo panorama jurídico nacional que envolve a judicialização da política e o ativismo judicial (SANTOS, 2011), o Poder Judiciário tem abandonado a vetusta justificativa de "separação de poderes" e tem enfrentado o tema com maior responsabilidade, cumprindo, ainda que embrionariamente, o seu papel de equilibrar o sistema jurídico, o que se depreende, por todos, do exemplo da novel interpretação dada pelo Supremo Tribunal Federal (BRASIL, 2011) ao direito à nomeação (BRASIL, 2011c) de candidatos aprovados em concurso dentro do quantitativo ofertado no edital.

Isso porque, percebeu-se que uma visão sistêmica rigorosa do Direito já redundou em severas limitações à concreção dos princípios constitucionais. Um exemplo interessante disso, que tange especificamente o tema abordado, era a antiga interpretação dada pelos Pretórios superiores brasileiros que entendiam ser uma expectativa de direito a nomeação em cargos que tiveram vagas "prometidas" no edital.

Mais do que uma evolução jurisprudencial, o que se constata é que os mencionados fundamentos já eram insustentáveis, diante do constitucionalismo hodierno. Ou não era de se concluir, a partir de noções das mais elementares de direito, que não é discricionário o dever da Administração nomear candidatos a cargos vagos (BRASIL, 2011a), sobretudo os propostos no edital do concurso?

O que se pretende nesse estudo é contribuir com uma ampliação do acervo conceitual do sistema jurídico relacionado ao tema concurso público, uma vez que, como se verá ao longo do trabalho, os conteúdos conceituais disponíveis - ou mesmo os já existentes -, mas não apropriadamente reconhecidos aos princípios constitucionais dirigidos à Administração Pública, não dão solução adequada às circunstâncias que se apresentam nesse truncado processo que é o preenchimento democrático dos cargos e empregos públicos.

Assim, o artigo está estruturado inicialmente com uma abordagem a partir da ótica constitucional acerca do procedimento do concurso público como instrumento materializador do direito fundamental à acessibilidade a cargos e empregos públicos. Em seguida, algumas considerações sobre a ausência de marco normativo que discipline o instituto "concurso público". Em tópicos posteriores, são analisadas as premissas constitucionais que polarizam a questão investigada. Após algumas análises descritivas de 
julgados que tiveram como objeto o tema proposto, nos quais se verificará os principais fundamentos de decisões que reconhecem, bem como as que negam eventual direito à convocação pessoal do candidato. Finalmente, se conclui o estudo com propostas de solução ao tema discutido.

\section{Do assento constitucional da acessibilidade aos cargos públicos}

Com o intento de fornecer ao leitor um breve subsídio acerca do tema acessibilidade ao cargo público, discorrer-se-á neste capítulo, sucintamente, sobre os contornos constitucionais, bem como sobre a natureza fundamental desse direito.

Já há muito os estudiosos do Direito constitucional chegaram à conclusão de que o papel da Constituição, sob a ótica do constitucionalismo liberal, impondo garantias negativas ao Estado frente o cidadão, não produziram condições aceitáveis de vida em sociedade, vale dizer, a concepção liberal não conseguiu afastar os problemas sociais decorrentes do individualismo, da concentração de renda (MAIA, 2011, p. 4). ${ }^{2}$

As promessas contidas nos textos constitucionais, portanto, não mais poderiam gerar falsas expectativas. Passa-se a exigir do Estado ações positivas na concretização das aspirações sociais positivadas nos textos Constitucionais.

Bem por isso, a doutrina passou a desenvolver uma nova perspectiva de constitucionalismo, denominada pela maioria dos estudiosos de neoconstitucionalismo (BARROSO, 2005) $)^{3}$. O que se nos interessa, para efeito desse estudo, é a eficácia jurídica das normas constitucionais reconhecidas por esse movimento, mais especificamente as propostas metodológicas de aplicabilidade desse pressuposto.

2 No mesmo sentido do texto, Maia conclui que: "A Constituição Federal de 1988, de matriz principiológica, nitidamente inspirada nas constituições lbéricas - frutos dos vitoriosos movimentos democráticos da década de 70 -, introduziu uma nova configuração no âmbito do direito público: um texto que extravasa os limites do constitucionalismo tradicional, de corte liberal, albergando na Lei Maior um extenso elenco de direitos fundamentais, bem como incorporando, através dos princípios, opções valorativas e, por meio de diretrizes, compromissos políticos." MAIA, Antonio Cavalcanti. As transformações dos sistemas jurídicos contemporâneos: apontamentos acerca do neoconstitucionalismo. 25 jun. 2007. Disponível em: http://www.mundojuridico.adv.br/cgi-bin/upload/Texto1159(2).pdf. Acesso em: 10 out. 2011, p. 4.

3 Por não ser o objeto do nosso estudo, não nos ateremos a todas as discussões desenvolvidas a partir da idéia de neoconstitucionalismo. Sobre o tema, Cf. BARROSO, Luís Roberto. Neoconstitucionalismo e constitucionalização do Direito. O triunfo tardio do Direito Constitucional no Brasil. Jus Navigandi, Teresina, ano 10, n. 851, 1 nov. 2005 Disponível em: http://jus.com.br/revista/texto/7547/neoconstitucionalismo-econstitucionalizacao-do-direito. Acesso em: 25 out. 2011. 
O que se propõe no neoconstitucionalismo, segundo Ana Paula de Barcellos, é conferir à norma constitucional uma normatividade consistente e utilizável na prática jurídica. A mencionada autora sintetiza a idéia da seguinte forma:

Em suma: a Constituição é norma jurídica central no sistema e vincula a todos dentro do Estado, sobretudo os Poderes Públicos. E, de todas as normas constitucionais, os direitos fundamentais integram um núcleo normativo que, por várias razões, deve ser especificamente prestigiado. (BARCELLOS, 2007, p. 9).

Eis a relevância da visão neoconstitucional para a compreensão mais acurada do presente estudo: a necessidade de se garantir a eficácia do direito fundamental à acessibilidade aos cargos e empregos públicos, de modo que essa norma não seja esvaziada em seus efeitos para benefício dos detentores do poder.

Como é amplamente corrente, os direitos fundamentais não estão enclausurados topograficamente no rol de direitos e garantias fundamentais da Constituição Federal, o que é assegurado pelo próprio legislador constituinte no artigo 5으, §2으 da Constituição da República Federativa do Brasil - CRFB. Portanto, enquanto corolário do princípio democrático e da igualdade, como bem assevera Fabrício Mota (2011), a acessibilidade aos cargos e empregos públicos enquadra-se tranquilamente como direito fundamental.

Essa é a mesma proposição de Adilson Abreu Dallari quando afirmou objetivamente que "a garantia de acessibilidade ao serviço público é um direito fundamental do cidadão" (2011, p. 1).

Quanto à fundamentalidade do direito à acessibilidade ao cargo público, não apenas a Doutrina o reconhece, mas também já se manifestou o Pretório Excelso da seguinte forma:

\footnotetext{
Nesses termos, a acessibilidade aos cargos públicos constitui um direito fundamental expressivo da cidadania, como bem observou a Ministra Cármen Lúcia na referida obra.

Esse direito representa, dessa forma, uma das faces mais importantes do status activus dos cidadãos, conforme a conhecida "teoria dos status" de Jellinek. (INFORMATIVO STF, 2011).
}

Importa frisar, nesse contexto, a relevância desse direito inclusive na ordem jurídica externa, uma vez que a Declaração Universal dos Direitos Humanos, em seu artigo XXI, "2", 
preconiza que: "Toda pessoa tem igual direito de acesso ao serviço público do seu país" (1948).

Para o alcance da eficácia desse direito fundamental, portanto, a constituição previu um procedimento para garantia da acessibilidade, o concurso público. Acerca do direito fundamental ao procedimento - que preferimos denominar como garantia fundamental -, leciona Gilmar Ferreira Mendes:

...como de outras, normalmente de índole normativa, destinadas a ordenar a fruição de determinados direitos ou garantias, como é o caso das garantias processuais constitucionais (direito de acesso à justiça, direito de proteção judiciária, direito de defesa). (MENDES, 2004, p. 8).

Considerando a conclusão parcial de que a acessibilidade aos cargos e empregos públicos, bem como o seu respectivo procedimento, o concurso público, possuem a natureza de direito e garantia fundamentais respectivamente, resta traçar notas acerca de normas que fomentarão a garantia de eficácia desses direitos, ante a ausência de marco regulatório.

Perquirir acerca do alcance do direito fundamental à acessibilidade aos cargos e empregos públicos, e, em decorrência disso, o conteúdo normativo desse princípio, conjugando-o com outros que igualmente informam a relação jurídica entre a Administração Pública e os administrados, conduz os operadores do direitos a diversas questões ainda sem solução definitiva no Direito brasileiro.

Pretende esse estudo contribuir com a solução de uma dessas questões.

\section{Da necessidade de normatização de questões relacionadas a concursos públicos}

$\mathrm{Na}$ ausência de regulação legislativa que disciplina essa relação jurídica potencialmente conflituosa que se estabelece entre a Administração Pública e os administrados candidatos a cargos e empregos públicos, é que se demanda uma atenção mais detida dos aplicadores do Direito na construção dos mecanismos que assegurem eficácia aos direitos fundamentais ora analisados.

A crítica que se faz a ausência de marco regulatório sobre o tema concurso público não ignora as iniciativas do Judiciário em sanar essa falta. A questão é que, por vezes, o 
próprio Judiciário se omite, negando eficácia ao direito fundamental de acesso ao cargo público, sob o argumento de que não cabe ao Poder Judicante a substituição do Legislativo.

Mas não é esse o maior problema que se identifica em razão dessa manifesta omissão legislativa. É que o Judiciário não possui apenas a função típica de julgar, mas também a de Administrador Público do seu próprio pessoal.

Ora, é inegável, portanto, o perigo que se corre de se conferir ao Judiciário a tutela integral da garantia constitucional do concurso público, que se revela como mecanismo mais democrático para o alcance da acessibilidade isonômica e republicana aos cargos e empregos públicos. Nesse mesmo sentido, corajosamente assevera Osório que:

\begin{abstract}
Sabemos que a tendência do Poder Judiciário é reconhecer campos largos de imunidade aos administradores que elaboram provas de ingresso às carreiras jurídicas, talvez até mesmo porque o próprio Judiciário - e, diga-se de passagem, também o Ministério Público, instituição fiscalizadora por excelência - realiza numerosos concursos públicos, não se revelando interessante propiciar abertura aos Juízes de primeiro grau no sentido de que pudessem efetuar controles mais rigorosos, fiscalizando atos de uma Banca Examinadora composta por autoridades superiores no plano administrativo. (OSÓRIO, 2010, p. 3).
\end{abstract}

Propusemo-nos, por tais motivos, a colaborar doutrinariamente com o Judiciário na limitação da discricionariedade do Administrador Público no ato de convocação dos candidatos, seja para fases (ou etapas) do certame, seja para nomeação no cargo.

Ainda sobre o prisma metodológico utilizado para o exame da questão proposta no estudo, saliente-se que a ausência de norma legal que observe os princípios constitucionais democratizantes do procedimento de acesso aos cargos e empregos públicos, tal como comentado alhures, nos conduz à apreciação da questão para além da concepção positivista de ordenamento jurídico.

O que se pretende, portanto, é contribuir na produção de novos conteúdos jurídicos a partir de análise de casos concretos sobre o tema estudado. Sobre essa metodologia, leciona Paulo Mendonça:

Em tais circunstâncias, o raciocínio tópico é de grande valia, pois a partir dele, poderia o julgador incorporar novos conteúdos ao ordenamento jurídico. Em verdade, o ordenamento seria algo em constante mutação e ampliação, de vez que ao direito positivo nele vigente, seriam constantemente agregadas novas normas, surgidas da aplicação do direito in concreto. (MENDONÇA, 1998, p. 3). 
Em função da ausência de marco regulatório que regulamente e procedimentalize os concursos públicos, buscar-se-á a harmonização da visão tradicional de sistema, praticamente reduzida à fórmula lógico-dedutiva, para utilização do raciocínio tópico,4 dada a relevância do processo de aplicação do direito na construção dogmática que se pretende no artigo.

A questão que se nos apresenta é: diante da discricionariedade da Administração Pública na condução desse procedimento que é o concurso público, pode o editalício prever a convocação dos aprovados em fases ou etapas, ou até definitivamente, apenas e tão somente por meio de atos publicados no sítio virtual do Órgão, ou até por ato exclusivamente publicado em Diário Oficial?

A construção dessa indagação, sob o ponto de vista da correção constitucional de uma resposta, a levar em consideração os valores a serem ponderados, seria: ante ao princípio democrático da acessibilidade, bem como sua conjugação com o princípio da publicidade e impessoalidade, é imperativa a convocação pessoal dos candidatos aos cargos públicos? É possível essa inferência do texto da Constituição Federal?

É constitucional a previsão editalícia que considera bastante a publicação em sítios virtuais de bancas examinadoras, ou até a convocação exclusivamente por Diários Oficiais?

\section{Do direito à convocação pessoal dos candidatos: uma análise descritiva dos principais argumentos que polarizam a questão}

Diante das questões ventiladas no capítulo anterior, cumpre-nos um dissecamento analítico das teses que fundamentam as decisões conflitantes dos Tribunais brasileiros.

Como mencionado na parte introdutória, nos capítulos seguintes passa-se à construção argumentativa de novos conteúdos jurídicos a partir da análise de casos concretos, mitigando a ótica da estrutura abstrata das normas, para propor maior grau de

\footnotetext{
A esse método de construção de conceitos jurídicos, denominado tópica, Karl Larenz "... Tópicos jurídicos serão, pois, argumentos utilizados na solução de problemas jurídicos, e que podem contar neste domínio com a concordância geral, o 'consensus omnium'. Poderão surgir de novo sob forma muito diversa. No Direito Civil romano assumiam a forma de decisões de casos, que eram abstraídas do caso decidido de tal modo que 'podiam facilmente ser reformuladas numa regra'. Também a Jurisprudência do "mos italicus", da baixa Idade Média, procedia 'topicamente'..." (1983, p. 172). LARENZ, Karl. Metodologia da Ciência do Direito. 2a ed. Lisboa: Fundação Calouste Gulbenkian, 1983, p. 172.
} 
concretude aos postulados e princípios que informam a acessibilidade aos cargos e empregos públicos.

Sobre a valia da tópica na ausência de marcos regulatórios, contribui a assertiva de Paulo Soares Mendonça, no sentido de que:

\begin{abstract}
Não há como se conceber, que o conteúdo conceitual de determinado ordenamento jurídico somente possa sofrer mudanças a partir de processo legislativo, sobretudo nos dias atuais, quando as alterações na sociedade se dão de forma acelerada, criando um sem número de situações, para as quais o tesouro legislativo existente não oferece solução. Assim, os processos de interpretação e de integração normativa, mais do que simples mecanismos de técnica jurídica, constituem verdadeiras fontes de alimentação normativa do sistema. (MENDONÇA, 1998, p. 8).
\end{abstract}

O cerne da discussão se dá na definição se há lesão a princípio constitucional quando cláusula editalícia prevê a convocação de candidato a cargo público exclusivamente por edital ou pelo sítio virtual da examinadora ou do Órgão que promove a seleção.

\title{
3.1 Da tese que nega o direito à convocação pessoal dos candidatos
}

O núcleo das decisões que negam o direito à convocação pessoal dos candidatos é extraído pela análise basicamente de um fundamento que sustenta não ser um dever da Administração a convocação pessoal dos candidatos aprovados em concurso público, que chega a se decompor em outros intrinsecamente a ele relacionados, mas do primeiro dependentes.

O argumento é de que, na ausência de imposição legal, a previsão editalícia discricionária poderia afastar validamente o dever de convocação pessoal dos candidatos aprovados, vez que, como é assente, o edital á a lei do concurso. ${ }^{5}$ Nessa tese, acrescentamse ainda argumentos dela decorrentes, no sentido de que a Administração de a prerrogativa discricionária de escolher a maneira mais conveniente de convocação dos candidatos; que a

\footnotetext{
Tecendo uma crítica à esta remansosa definição do Supremo, Agapito Jr. registra que:"A Administração Pública, quando necessitar prover cargos, empregos ou funções públicas, precisará desenvolver todo um procedimento administrativo, o qual se deflagra com a publicidade inerente ao regulamento do concurso. $O$ instrumento de publicidade é justamente o edital (continete); o regulamento ou normas nele veiculadas (conteúdo) é que regem o concurso público; portanto, data máxima vênia, é uma imprecisão técnica dizerse que o edital é a norma do certame" MACHADO JÚNIOR, Agapito. $O$ controle jurisdicional nos concursos públicos. 2006. 287 p. Dissertação (Mestrado em Direito Público). Universidade Federal do Ceará. Fortaleza, p. 177-178.
} 
inscrição do candidato no concurso presume a concordância com as normas editalícias, nestas incluídas a convocação por Diário Oficial ou Internet.

Foi com esse fundamento que a jurisprudência indeferiu pleitos que pugnavam o direito de convocação pessoal. A título exemplificativo, veja-se:

\begin{abstract}
ADMINISTRATIVO. MANDADO DE SEGURANÇA. CONCURSO PÚBLICO. NOMEAÇÃO E POSSE. PRAZO. PRINCÍPIO DA PUBLICIDADE RESPEITADO. I - A publicação regular do ato de nomeação de candidato aprovado em concurso público é bastante para a observância do princípio da publicidade dos atos administrativos, fluindo, a partir daí, o prazo para a posse respectiva. A notificação pessoal do aludido candidato é medida dispensável à regularidade da convocação, mormente quando este se encontra ausente do país. II - Apelação desprovida. (BRASIL, 2003).
\end{abstract}

ADMINISTRATIVO. CONCURSO PÚBLICO. PERDA PRAZO PARA REALIZAÇÃO EXAME MÉDICO. COMPROVAÇÃO DA CONDIÇÃO DE DEFICIENTE. AUSÊNCIA DE JUSTIFICATIVA PLAUSíVEL. 1. De acordo com o pacífico entendimento da doutrina e da jurisprudência, o edital é a lei de regência do certame, vinculante para a Administração e para o candidato. A Administração, dentro do âmbito de seu poder discricionário, tem a liberdade de fixar os critérios e normas nele constantes. Ao Poder Judiciário, por sua vez, reserva-se o exame da legalidade ou constitucionalidade dessas normas, sem adentrar no juízo de conveniência e oportunidade decorrentes desse poder discricionário. 2. Consta do item 12.2 do edital do concurso ser de inteira responsabilidade do candidato acompanhar a publicação de todos os atos, editais e comunicados referentes ao concurso público que sejam divulgados no Diário Oficial da União e na Internet, não havendo referência acerca da necessidade de realização de comunicação pessoal. 3 . Publicado o ato convocatório, não há que se falar em restabelecimento de novo prazo em favor do Demandante, uma vez que não foi apresentada nenhuma justificativa plausível para afastar a perda do prazo pelo candidato, a quem caberia o acompanhado das publicações oficiais disponibilizadas em endereço eletrônico. 4. A convocação foi realizada com antecedência suficiente para que o Apelante tomasse conhecimento do ato e comparecesse ao local de realização do exame médico, mormente quando se trata de exame a ser realizado no local onde reside $o$ Recorrente. 5. Apelação não provida. (BRASIL, 2010b).

Como visto, a discricionariedade do Administrador Público na confecção do editalício é o argumento fundamental da tese que rejeita o dever de convocação pessoal dos candidatos.

Aqui, ao que tudo indica, parece-nos que conferir tamanho espaço de discricionariedade na confecção de editalícios conduz os administradores mais do que a uma valoração de conveniência e oportunidade, mas a prerrogativa de opções por "arbítrios" políticos. 


\subsection{Dos fundamentos que sustentam o direito à convocação pessoal dos candidatos}

Os argumentos que fundamentam o dever de convocação pessoal do candidato, por sua vez, podem ser sintetizados, com pequenas variações, em três vetores.

O primeiro preconiza que qualquer convocação de aprovado em concurso público deverá observar a regra da convocação pessoal, eis que a publicação via internet e em Diário Oficial possuem natureza meramente informativa, pelo que a não convocação pessoal do candidato viola o princípio da publicidade, dentre outros.

É um argumento que já encontra acolhida no STJ, que, para os fins metodológicos desse estudo, tomaremos como caso paradigmático.6 Leia-se:

AGRAVO REGIMENTAL. RECURSO ORDINÁRIO. MANDADO DE SEGURANÇA. ADMINISTRATIVO. CONCURSO PÚBLICO. CONVOCAÇÃO MEDIANTE PUBLICAÇÃO NO DIÁRIO OFICIAL. PRINCÍPIOS DA PUBLICIDADE E DA RAZOABILIDADE. NÃO OBSERVÂNCIA. PRECEDENTES.

1. Muito embora não houvesse previsão expressa no edital do certame de intimação pessoal do candidato acerca da sua convocação, em observância aos princípios constitucionais da publicidade e da razoabilidade, a Administração Pública deveria convocar pessoalmente o candidato, para que pudesse exercer, se fosse de seu interesse, seu direito à nomeação e posse.

2. De acordo com o princípio constitucional da publicidade, insculpido no art. 37, caput, da Constituição Federal, é dever da Administração conferir aos seus atos a mais ampla divulgação possível, principalmente quando os administrados forem individualmente afetados pela prática do ato. Precedentes.

3. Agravo regimental improvido. (BRASIL, 2011b).

É o que igualmente se depreende do seguinte julgados do TRF da 1ạ Região:

ADMINISTRATIVO. CONCURSO PÚBLICO PARA O PROVIMENTO DE CARGO DE POLÍCIA RODOVIÁRIA FEDERAL. NULIDADE DA SENTENÇA RECORRIDA REJEITADA. MATRÍCULA NO CURSO DE FORMAÇÃO. PERDA DO PRAZO. CONVOCAÇÃO FEITA EXCLUSIVAMENTE PELA INTERNET. AFRONTA AOS PRINCÍPIOS DA ISONOMIA E DA PUBLICIDADE. ILEGITIMIDADE.

I - Não há que se falar em nulidade da sentença, sob o fundamento de que o julgado não apreciou a matéria de fundo da demanda, pois, em virtude do disposto no art. 515, § 10, do CPC, cabe ao Tribunal a apreciação de todas as questões suscitadas e discutidas no processo, ainda que a sentença não as tenha julgado por inteiro, desde que sejam devolvidas, integralmente, em recurso, para apreciação pelo Tribunal, como no caso.

6 Segundo Humberto Ávila, casos paradigmáticos são aqueles cuja solução pode ser havida como exemplar, considerando-se exemplar aquela solução que serve de modelo para a solução de outros tantos casos em virtude da capacidade de generalização do seu conteúdo valorativo $(2005$, p. 5). ÁVILA, Humberto. Moralidade, Razoabilidade e Eficiência na Atividade Administrativa, Revista Eletrônica de Direito do Estado (REDE), Salvador, no 4, out./nov./dez. 2005. Disponível em: http://www.direitodoestado.com/revista/REDE4-OUTUBRO-2005-HUMBERTO\%20AVILA.pdf. Acesso em: 10 nov. 2011. 
II - Afronta os princípios da publicidade e da isonomia a convocação do candidato, realizada pela Internet, para a matrícula na segunda etapa do Concurso Público para o cargo de Polícia Rodoviária Federal (Curso de Formação), a ser formalizada, também, exclusivamente, por meio eletrônico, posto restringir a aludida notificação apenas aos candidatos que têm acesso à Internet, em detrimento daqueles que não o possuem.

III - Apelação e remessa oficial desprovidas. Sentença confirmada. (BRASIL, 2008a).

Foi nesse mesmo sentido que o mencionado tribunal, no caso analisando uma seleção pública para ingresso em universidade, ementou:

ADMINISTRATIVO. APELAÇÃO CÍVEL. ENSINO SUPERIOR. APROVAÇÃO EM VESTIBULAR. MATRÍCULA INTEMPESTIVA. DIVULGAÇÃO EXCLUSIVAMENTE PELA INTERNET. PERDA DO PRAZO. OFENSA AO PRINCÍPIO DA PUBLICIDADE. CARACTERIZAÇÃO.

I - Comprovado nos autos que a perda do prazo fixado pela instituição de ensino para a realização da matrícula, em virtude de aprovação em regular processo seletivo, deu-se por circunstâncias alheias à vontade da aluna, uma vez que a convocação para a referida matrícula ocorreu exclusivamente pela internet, não há dúvida de que, além de violar o princípio da publicidade, impede aos candidatos carentes o acesso à universidade, como na hipótese dos autos.

II - Apelação e remessa oficial desprovidas. Sentença mantida. (BRASIL, 2009a).

O segundo argumento não nega peremptoriamente a validade de previsão de atos convocatórios exclusivamente pela Internet ou por publicação em Diários Oficiais, mas condicionam a validade dessas convocações à publicação conjunta do edital com um cronograma completo do certame.

Argumenta-se que é desarrazoada a exigência de que o candidato leia a imprensa oficial diariamente em busca do resultado do concurso. Desarrazoabilidade que só seria afastada pela aludida publicação conjunta do edital com o cronograma completo do certame.

ADMINISTRATIVO. ENSINO. PERDA DA MATRÍCULA. CURSO DE MEDICINA. EDITAL DE RECLASSIFICAÇÃO DIVULGADO 6 MESES APÓS O PRIMEIRO, SOMENTE VIA INTERNET. OFENSA AO PRINCÍPIO DA PUBLICIDADE.

1. A impetrante foi convocada pelo Edital de Reclassificação $n \circ 5$, de 20/08/2007, para efetuar matrícula no curso de Medicina, na UFJF/MG, seis meses após o primeiro Edital ter sido publicado.

2. Não se afigura razoável exigir que um candidato faça consulta diária na internet após decorrido um lapso temporal tão grande, sem que haja um calendário 
programado da divulgação dos demais editais de reclassificação. Precedentes desta Corte.

3. Verifica-se que houve violação ao princípio da publicidade na medida em que a divulgação, sendo exclusiva pela internet, sem um calendário fixo com as datas programadas dos editais de reclassificação a serem publicados, impediu candidatos com menor poder aquisitivo de terem ciência da sua convocação, como (sic) in casu.

4. Apelação e remessa improvidas. (BRASIL, 2009b).

Uma terceira corrente, essa com aceitação mais ampla no Superior Tribunal de Justiça, preconiza que a convocação exclusivamente em sítio virtual ou em Diário Oficial é valida, exceto na hipótese de se "transcorrer considerável de lapso temporal". É o que se decidiu no aresto seguinte:

ADMINISTRATIVO. RECURSO ORDINÁRIO EM MANDADO DE SEGURANÇA. CONCURSO PÚBLICO. CONVOCAÇÃO PARA NOVA ETAPA. EDITAL PUBLICADO EM DIÁRIO OFICIAL. LONGO LAPSO TEMPORAL ENTRE O TAL CHAMAMENTO E A REALIZAÇÃO DA FASE IMEDIATAMENTE ANTERIOR. PRINCÍPIO DA RAZOABILIDADE.

1. Trata-se de mandado de segurança impetrado por candidato aprovado em concurso público contra ato que o teria excluído do certame. O impetrante recorrente alega que, apesar de ter tomado conhecimento da sua aprovação na primeira etapa do concurso por meio de edital, somente nove meses após isso é que houve a convocação para a perícia médica. Entende violado seu direito, por não ter sido intimado pessoalmente para a avaliação médica.

2. Há entendimento pacífico nesta Corte no sentido de que caracteriza violação ao princípio da razoabilidade a convocação para determinada fase de concurso público apenas mediante publicação do chamamento em diário oficial quando passado considerável lapso temporal entre a realização ou a divulgação do resultado da etapa imediatamente anterior e a referida convocação, uma vez que é inviável exigir que o candidato acompanhe, diariamente, com leitura atenta, as publicações oficiais.

3. Na espécie, o recorrente foi convocado para a avaliação de títulos do certame em edital publicado em 27.1.2009, sendo convocado genericamente nesse mesmo edital para avaliação médica em 1.9.2009.

4. E, mesmo não havendo previsão expressa no edital do certame de intimação pessoal do candidato acerca de sua nomeação, em observância aos princípios constitucionais da publicidade e da razoabilidade, a Administração Pública deveria, mormente em face do longo lapso temporal decorrido entre as fases do concurso (mais de 8 meses), comunicar pessoalmente o candidato sobre a nova fase, para que pudesse exercer, se fosse de seu interesse, o exame médico.

5. Recurso ordinário em mandado de segurança provido.

Acórdão: Vistos, relatados e discutidos esses autos em que são partes as acima indicadas, acordam os Ministros da SEGUNDA TURMA do Superior Tribunal de Justiça, na conformidade dos votos e das notas taquigráficas, o seguinte resultado 
de julgamento: "A Turma, por unanimidade, deu provimento ao recurso ordinário, nos termos do voto do Sr. Ministro-Relator, sem destaque."

Os Srs. Ministros Castro Meira, Humberto Martins e Herman Benjamin (Presidente) votaram com o Sr. Ministro Relator. Não participou, justificadamente, do julgamento o Sr. Ministro Cesar Asfor Rocha. (BRASIL, 2011d).

Outras celeumas exemplificam a repercussão da não adoção da convocação pessoal dos candidatos como regra para assegurar efetivamente a acessibilidade aos cargos públicos.

Algumas decisões, essas mais casuísticas, consideraram igualmente nula a ausência da convocação pessoal do candidato.

A primeira (BRASIL, 2011f), considerou inválido o ato de convocação impessoal pela adoção de critérios diferenciados entre a primeira e a segunda etapa do concurso, além do fato de o candidato que impugnou o ato de convocação ter domicílio profissional em local de difícil acesso, o que dificultaria o acesso à internet e às publicações em Diário Oficial.

A segunda decisão (BRASIL, 2008b), a seu turno, invalidou a convocação impessoal porquanto a Administração dispensou tratamento diferenciado a alguns candidatos, de modo que convocou pessoalmente uns e não outros.

Por fim, o terceiro aresto (BRASIL, 2009c) invalidou convocação exclusivamente pela internet por ser o candidato deficiente visual.

Até aqui, portanto, tentamos desenlear os principais fundamentos que dirigiram os Órgãos Julgadores a favor e contra a convocação pessoal dos candidatos em concursos públicos. Não se tratou de exame jurisprudencial exaustivo, mas meramente exemplificativo, a fim de ilustrar algumas particularidades do tema em estudo.

Doravante, o articulista proporá uma solução adequada do ponto de vista constitucional, de modo que obtenha mais efetividade dos princípios constitucionais envolvidos na questão.

\section{Do direito à convocação pessoal dos candidatos - uma análise crítica}

Antes da exposição de motivos pelos quais o articulista considera uma opção constitucionalmente adequada e a outra não, incumbe-nos esclarecer os pressupostos metodológicos que culminaram nessa reflexão. 
Quando o Judiciário a pretexto de observar a "separação dos poderes", ou de respeitar a "discricionariedade administrativa", opta por criar campos largos de imunidades na seara dos concursos públicos, opta também por ignorar os anseios populares plasmados no texto constitucional, a favor da manutenção secular de favoritismos e privilégios de poucos em detrimento de muitos no Brasil.

Ainda subsidiando preliminarmente o leitor acerca da relevância das decisões institucionais sobre o tema debatido, oportuna e muito realista a assertiva de Dallari quanto ao caráter democrático do tema, quando assevera que "O concurso público somente interessa aos fracos, aos desprotegidos, àqueles que não contam com o amparo dos poderosos capazes de conseguir cargos ou empregos sem maiores esforços." (2006, p. 6).

Como já foi verificado nesse estudo, a discricionariedade do Administrador Público na confecção do editalício é o argumento fundamental da tese que rejeita o dever de convocação pessoal dos candidatos.

Ocorre que discricionariedade não pode ser tida como sinônimo de arbítrio. Nesse aspecto, para rememorar os limites de escolha de conveniência e oportunidade da Administração, salutar a lição de Bandeira de Mello de que:

\begin{abstract}
... discricionariedade é liberdade dentro da lei, nos limites da norma legal, e pode ser definida como a margem de liberdade conferida pela lei ao administrador a fim de que este cumpra o dever de integrar com sua vontade ou juízo a norma jurídica diante do caso concreto, segundo critérios subjetivos próprios, a fim de dar satisfação aos objetivos consagrados no sistema legal. Não se confundem discricionariedade e arbitrariedade. Ao agir arbitrariamente, o agente estará agredindo a ordem jurídica, pois terá se comportado fora do que lhe permite a lei. Seu ato, em conseqüência, é ilícito e por isso mesmo corrigível judicialmente [...]. Em rigor, não há, realmente, ato algum que possa ser designado, com propriedade, como ato discricionário, pois nunca o administrador desfruta de liberdade total. 0 que há é exercício de juízo discricionário quanto à ocorrência ou não de certas situações que justificam ou não certos comportamentos e opções discricionárias quanto ao comportamento mais indicado para dar cumprimento ao interesse público in concreto, dentro dos limites em que a lei faculta a emissão deste juízo ou desta opção. (2001, p. 385).
\end{abstract}

Do ponto de vista metodológico, a ciência jurídica também pode limitar subjetivismos aleatórios nessa questão, posto que, como visto na descrição de fundamentos jurisprudenciais, já houve diversos embróglios contribuindo para um estado injustificável de insegurança jurídica. 
Valemo-nos da proposição de Humberto Ávila sobre soluções que se atêm exclusivamente à apreciação de validade superficial, verbis:

O leitor aplicado também poderá perceber que o presente estudo termina por afiançar um conceito de direito que inclui entre seus elementos não apenas a correta edição de fontes normativas por autoridades competentes, mas também, pelas definições de princípios e de postulados aqui propostas, a correção concreta dos conteúdos dessas mesmas fontes. $(2005$, p. 3).

Dessarte, propõe-se uma perspectiva que parte do pressuposto de que há um dever do Administrador Público em optar por disposições editalícias comprometidas com os postulados da razoabilidade e de proporcionalidade, bem assim os princípios da publicidade, isonomia e impessoalidade, que compõe a eficácia da acessibilidade aos cargos e empregos públicos.

\subsection{Do direito à convocação pessoal dos candidatos - aplicação do postulado da proporcionalidade}

O objetivo desse estudo é propor uma análise racionalmente controlável dos princípios constitucionais que vincularão a Administração Pública na procedimentalização de concursos públicos, notadamente no que toca à convocação pessoal dos candidatos concursandos.

As decisões que polarizaram a questão, com diferentes fundamentos, giraram em torno da publicidade. Portanto, resta patente a necessidade de reflexão acerca do princípio da publicidade, a partir de uma análise que mitigue os subjetivismos a respeito do que se entende por obediência a esse princípio.

Com o fito de descortinar o comportamento indispensável a realizar o valor da acessibilidade a cargos e empregos públicos observando-se adequadamente o princípio da publicidade, adotar-se-á, para efeitos dessa investigação, a distinção proposta por Humberto Ávila entre princípios e postulados.

Para o autor, princípios possuem natureza finalísticas, que consistem em: 
prescrição indireta de comportamentos cujos efeitos são havidos como necessários àquela realização. $(2005$, p. 4).

Os postulados, por sua vez, carecem desse aspecto finalístico, porquanto despidos de forma e conteúdo, servindo para estruturar a aplicação de princípios, de modo que, a rigor, violados são os princípios,7 e não os postulados. Assim, segundo Ávila, o postulado "... os postulados não descrevem comportamentos, mas estruturam a aplicação de normas que o fazem." (2005, p. 8).

As decisões que pugnaram ser um dever da Administração de convocar pessoalmente os candidatos defenderam a violação aos princípios da razoabilidade e publicidade.

Como se pode ver, de acordo com as premissas desse estudo, o que foi violado foi o princípio da publicidade. A razoabilidade, enquanto postulado, apenas contribui no esforço argumentativo para definição do comportamento indispensável à conservação dos valores intrínsecos ao princípio da publicidade.

Ocorre que o postulado que servirá para análise estruturante do conceito normativo de dever de convocação pessoal de candidatos aprovados em concurso não é o da razoabilidade,8 mas o da proporcionalidade. 9

Ocorre que o que se pretende é a perseguição de uma regra que adeque o meio empregado para cumprir a o dever de publicidade à realização dos fins, acessibilidade democrática ao cargo público. Considerando essa evidente relação de causalidade, importa a

7 Nesse perspectiva, assevera o autor que: "Só elipticamente é que se pode afirmar que são violados os postulados da razoabilidade, proporcionalidade ou da eficiência, por exemplo. A rigor, violadas são normas - princípios e regras - que deixaram de ser devidamente aplicadas." (ÁVILA, 2005, p. 8).

8 "Ocorre que a razoabilidade, de acordo com a reconstrução aqui proposta, não faz referência a uma relação de causalidade entre um meio e um fim, tal como o faz o postulado da proporcionalidade." (ÁVILA, 2005, p. 18).

9 "O dever de proporcionalidade, então, estabelece uma estrutura formal de aplicação dos princípios envolvidos: o meio escolhido deve ser adequado, necessário e não-excessivo. Sobre a medida de excesso considerada inválida o dever de proporcionalidade nada diz. Só a análise diante do caso concreto e diante da relevância que o ordenamento jurídico atribui a determinados bens jurídicos ( $p$. ex. vida, dignidade, liberdade, propriedade) pode revelar o excesso da medida. A aplicação concreta só se completa com um conteúdo, até porque os fins só podem ser estabelecidos em contato com normas substanciais. O que importa, entretanto, é que não é o dever de proporcionalidade em si que estabelece a medida substancial da excessividade, mas sua aplicação conjunta com outros princípios materiais. Vale dizer: o dever de proporcionalidade, ao contrário do que pretende LARENZ, seria um princípio ou critério formal, como bem assinalou KAUFMANN." (ÁVILA, 2001, p. 24-25). 
utilização do postulado da proporcionalidade, de modo que, adotando-se o meio, promovase o fim.

Por conseqüência, o postulado da proporcionalidade exige que a Administração escolha, para a convocação dos candidatos em concurso, meios adequados, necessários e proporcionais em sentido estrito. Passemos ao exame de cada um desses elementos em relação ao dever de convocação pessoal de candidatos em concursos públicos.

Com efeito, analisar-se-á, com base nos julgados mencionados no estudo, o meio utilizado (convocação do candidato pelo sítio virtual ou Diário Oficial), o fim buscado (princípio da publicidade, isonomia e acessibilidade ao cargo e emprego público) e o princípio colateralmente atingido (potencialmente publicidade, isonomia, impessoalidade, moralidade).

O dever de adequação indica que o meio empregado na atuação deve promover o fim colimado.

A convocação de candidatos aprovados em concursos públicos pela internet ou pelo Diário Oficial atende à promoção da publicidade?

Por vezes sim, sobretudo quando essas convocações se dão pela internet, já que boa parcela da população possui acesso. Da mesma forma, quando não há grande lapso temporal entre a realização do certame e a convocação dos aprovados, as convocações impessoais atendem à finalidade pretendida.

O dever de necessidade, por sua vez, consiste na adoção de meio menos gravoso ou oneroso, dentre os meios igualmente adequados, para alcançar o fim público, vale dizer, o meio escolhido é o que causa a menor restritividade em relação aos direitos fundamentais.

No exame dos casos discutidos nos tribunais, os editais dos concursos obrigavam os candidatos a acompanhar eventuais publicações na internet ou Diário Oficial.

Considerando a heterogeniedade econômica da população brasileira, pode-se concluir que todos possuem a mesma condição de acessibilidade diária à internet, ou tempo e condições de acompanhamento de Diários Oficiais? Ou seja, é razoável exigir que o universo de excluídos digitais acompanhem as publicações pela internet - na ausência de qualquer prazo previamente assinalado - sem que isso importe em verdadeira afronta ao princípio da isonomia e acessibilidade aos cargos públicos? 
Os elevados preços cobrados pelas entidades organizadoras de concursos públicos não comportam a convocação pessoal por meio de correspondência aos aprovados nas etapas/fases ou convocações em definitivo? Esse seria um argumento capaz de ilidir a incidência do comando constitucional?

O dever de proporcionalidade em sentido estrito, por fim, é observado quando as vantagens a serem conquistadas superarem as desvantagens provocadas.

A economia de recursos e de tempo na opção de publicação pela internet ou Diário Oficial representam as vantagens aparentes na convocação impessoal.

A potencialidade de dano aos candidatos, efetivamente demonstrada pelos litígios instaurados sob os mais diversos fundamentos, justifica a economia de recursos e de tempo por parte da Administração Pública?

Parece evidente que, malgrado a convocação pela internet ou Publicação em Diário Oficial possa ser considerada adequada para conferir publicidade aos atos de convocação a maioria dos candidatos em concursos públicos, o mesmo não se pode concluir, como visto, em relação aos elementos necessariedade e proporcionalidade em sentido estrito.

Com efeito, do ponto de vista teleológico, a regra em comento se mostra como corolária dos princípios da publicidade, isonomia, e acessibilidade aos cargos públicos. A finalidade do dever de convocação pessoal dos candidatos é que se garanta ao cidadão, mesmo aos que não possuem condições de acompanhar as publicações em Diário Oficial ou em sítios virtuais, a possibilidade de galgar o tão sonhado cargo público.

No que toca a indigitada discricionariedade administrativa eventualmente violada, sabe-se que o desenvolvimento da atividade administrativa demanda um espaço de escolhas que compreendem a valoração do binômio conveniência e oportunidade. É por tal motivo que o juiz, via de regra, não deve substituir a escolha do gestor público.

Diante disso, pode-se indagar: poderá o judiciário imiscuir-se em decisão eminentemente administrativa de como se conduzirá o certame? Pode o Judiciário invalidar norma editalícia que obriga o acompanhamento de convocações pela internet ou Diário Oficial? Parece-nos que a resposta positiva a essa indagação é o único meio de se garantir a eficácia dos princípios constitucionais envolvidos. 
Diante da argumentação utilizada nas decisões, entende-se que só há uma hipótese que poderia afastar o dever de convocação pessoal dos candidatos, qual seja, a previsão editalícia de cronograma previamente estipulado dessas convocações.

Isso porque a adoção dessa providencia observaria a isonomia, uma vez que os candidatos que eventualmente não possuam condições de acesso à internet ou a publicações de Diários Oficiais poderiam razoavelmente se programar para ter acesso na data previamente agendada pela Administração Pública.

\section{Conclusão}

O presente estudo procurou demonstrar, inicialmente, os malefícios da carência de disciplina legal dos deveres da Administração Pública na procedimentalização dos Concursos Públicos.

Em seguida, demonstrou-se o assento constitucional da acessibilidade aos cargos e empregos públicos, sua natureza fundamental, bem como uma breve exposição do conteúdo normativo dos princípios constitucionais àquele correlatos.

Procurou-se demonstrar a necessidade de eficácia aos princípios constitucionais, a partir de idéias como as propugnadas pelo neoconstitucionalismo. Do ponto de vista da metodologia da ciência jurídica, ressaltou-se a relevância do método tópico, visto que o conceito normativo proposto no estudo se originou não apenas do método dedutivo, a partir do sistema principiológico positivado na Constituição, mas também da análise de casos concretos, conciliando o método sistemático ao problemático.

A partir de uma análise descritiva de julgados que polarizavam o debate de um lado a outro, com a exposição dos principais fundamentos que rechaçavam e admitiam o dever de convocação pessoal de candidatos a cargos e empregos públicos, passou-se a uma reflexão crítica das decisões, em busca de uma solução ideal do ponto de vista constitucional, privilegiando-se a maior eficácia dos princípios constitucionais envolvidos.

Em busca da solução que conciliasse adequadamente os princípios constitucionais envolvidos, foram utilizadas as distinções entre as categorias princípios e postulados. Procurou-se, então, a separação do método investigativo que privilegia tão apenas os aspectos valorativos dos princípios - uma vez que ambas as decisões pressupunham correção 
entre os princípios envolvidos, precipuamente o da publicidade -, priorizando-se a capacidade estruturante dos postulados na aplicação de princípios e regras.

Para concluir sobre a existência ou não do dever convocação pessoal de candidatos em concursos públicos, inferiu-se a necessidade de adequação entre meios e fins adotados pela Administração Pública, a partir dos elementos do postulado da proporcionalidade, a fim de propor uma solução a um só tempo: segura, definitiva e constitucionalmente ideal.

À guisa de conclusão, estabeleceu-se que a convocação impessoal dos candidatos por meio de internet ou publicações em Diário Oficial poderia atender, ainda que parcialmente, ao elemento adequação, porque a maior parte dos candidatos poderiam tomar conhecimento das convocações. No entanto, o mesmo não ocorreu com a análise dos elementos necessidade e proporcionalidade em sentido estrito.

Dentre os meios igualmente adequados para alcançar o fim público, a adoção da convocação impessoal do candidato não atende ao dever de necessidade, visto que o meio escolhido causa restrições desnecessárias aos direitos fundamentais envolvidos, dentre os quais a publicidade e a isonomia.

Ademais, as vantagens de economia de tempo e de recursos na convocação impessoal dos candidatos, ou uma turva proteção à discricionariedade administrativa na escolha no processo de convocação impessoal dos candidatos, com segura tranqüilidade, não superam as desvantagens que provoca.

Isso porque, como visto no estudo, não se pode razoavelmente supor que a totalidade dos candidatos a concursos públicos nos diversos entes federados do país possuem acesso regular e irrestrito, tanto ao ambiente virtual da internet, quanto às publicações em Diários Oficiais.

Isso sem mencionar outras possibilidades de atentado contra a isonomia que podem ser gerados pelo mecanismo da convocação impessoal, como nos citados arestos em que se anulou convocação por Diário Oficial de pessoa com deficiência visual, ou ainda na hipótese de convocação impessoal a alguns candidatos, e de forma diversa (convocação pessoal) a outros.

Por todas as razões ventiladas no texto, conclui-se que, à luz do princípio constitucional da acessibilidade aos cargos e empregos públicos, é dever da Administração Pública, independente de previsão editalícia, a convocação pessoal do candidato no 
endereço declinado quando da inscrição no certame, tanto para fases do concurso, quanto para a nomeação para ocupação da vaga.

\section{Referências}

ÁVILA, Humberto. A distinção entre princípios e regras e a redefinição do dever de proporcionalidade. Revista Diálogo Jurídico, Salvador, v. 1, n. 4, jul. 2001. Disponível em: <http://www.direitopublico.com.br/revistas/10302806/dialogo-juridico-04-julho-2001humberto-avila.pdf>. Acesso em: 03 ago. 2011.

Moralidade, Razoabilidade e Eficiência na Atividade Administrativa. Revista Eletrônica de Direito do Estado (REDE), Salvador, n. 4, out./dez. 2005. Disponível em: <http://www.direitodoestado.com/revista/REDE-4-OUTUBRO-2005-HUMBERTO\%20 AVILA.pdf>. Acesso em: 10 nov. 2011.

Teoria dos princípios. Da definição à aplicação dos princípios jurídicos. 3. ed. São Paulo: Malheiros, 2003.

BANDEIRA DE MELLO, Celso Antônio. Curso de Direito Administrativo. 13. ed. São Paulo: Malheiros Editores, 2001.

BARROSO, Luís Roberto. Neoconstitucionalismo e constitucionalização do Direito: O triunfo tardio do Direito Constitucional no Brasil. Jus Navigandi, Teresina, v. 10, n. 851, novembro, 2005. Disponível em: <http://jus.com.br/revista/texto/7547/ neoconstitucionalismo-econstitucionalizacao-do-direito>. Acesso em: 25 out. 2011.

BERCELLOS, Ana Paula. Neoconstitucionalismo, Direitos Fundamentais e Controle de políticas públicas. Revista Diálogo Jurídico, Salvador, n. 15, jan./mar. 2007. Disponível em: $<$ http://www.direitopublico.com.br/pdf_seguro/artigo_controle_pol_ticas_p_blicas_.pdf $>$. Acesso em: 10 nov. 2011.

BRASIL. Superior Tribunal de Justiça. Mandado de Segurança 24660, Tribunal Pleno. Relator: Ministra Elen Gracie. 03 fev. 2011. DJe - 183 DIVULG 22-09-2011 PUBLIC 23-09-2011 EMENT VOL-02593-01 PP-00001. Disponível em:

<http://www.stf.jus.br/portal/jurisprudencia/listarJurisprudenciaDetalhe.asp?s1=000179720 \&base=baseAcordaos $>$. Acesso em: 10 nov. 2011.

BRASIL. Superior Tribunal de Justiça. Agravo Regimental no Recurso em Mandado de Segurança 23467 - PR 2007/0003730-0. Tribunal da Sexta Turma. Relator: Ministra Maria Thereza de Assis Moura. 15 mar. 2011. DJe 25 mar. 2011. Disponível em: <http://www.jusbrasil.com.br/filedown/dev5/files/JUS2/STJ/IT/AGRG-RMS_ 23467_PR_1302020196950.pdf>. Acesso em: 12 nov. 2011.

BRASIL. Superior Tribunal de Justiça. Recurso Extraordinário 598099/MS, Tribunal Pleno. Relator: Ministro Gilmar Mendes. 10 ago. 2011. DJe - 189 DIVULG 30-09-2011 PUBLIC 03-102011 EMENT VOL-02599-03 PP-00314. Disponível em: 
<http://www.stf.jus.br/portal/jurisprudencia/listarJurisprudenciaDetalhe.asp?s1=000180263 \&base=baseAcordaos $>$. Acesso em: 10 nov. 2011.

BRASIL. Superior Tribunal de Justiça. Recurso Ordinário em Mandado de Segurança 2011/0103387-0 - RMS 34404/ES. Tribunal da Segunda Turma. Relator: Ministro Mauro Campbell Marques. 06 set. 2011. DJe 14 set. 2011. Disponível em: <https://ww2.stj.jus.br/revistaeletronica/Abre_Documento.asp?sSeq=1086470\&sReg=2011 01033870\&sData=20110914\&formato=PDF> . Acesso em: 12 nov. 2011.

BRASIL. Tribunal Regional Federal da 1ạ Região. Apelação em Mandado de Segurança 199801000145427. Tribunal da Sexta Turma. Relator: Desembargador Federal Souza Prudente. 12 ago. 2003. Disponível em:

<http://arquivo.trf1.jus.br/default.php?p1=199801000145427>. Acesso em: 12 nov. 2011.

BRASIL. Tribunal Regional Federal da 1ạ Região. Apelação em Mandado de Segurança 200534000114541. Tribunal da 4a Turma. Relator: Juiz Federal Márcio Barbosa Maia. 14 set. 2011. E-DJF1, Brasília, no 175, ano 3, 14 set. 2011, p.204-205. Disponível em: <http://arquivo.trf1.jus.br/default.php?p1=200534000114541>. Acesso em: 17 nov. 2011.

BRASIL. Tribunal Reginal Federal 1a Região. Apelação Cível 2006.33.03.000227-0/BA. Tribunal da Sexta Turma. 12 fev. 2008. Disponível em: <http://arquivo.trf1.jus.br/default.php?p1=200633030002270>. Acesso em: 12 nov. 2011.

BRASIL. Tribunal Regional Federal 1a Região. Apelação Cível 2006.35.00.017637-5/GO. Tribunal da Sexta Turma. Relator: Desembargador Federal Souza Prudente. 16 fev. 2009. Disponível em: <http://arquivo.trf1.jus.br/default.php?p1=200635000176375>. Acesso em: 12 nov. 2011.

BRASIL. Tribunal Regional Federal 1a Região. Apelação Cível 2007.38.01.005810-4/MG. Tribunal da Quinta Turma. Relator: Desembargadora Federal Selene Maria de Almeida. 05 jun. 2009. Disponível em: <http://arquivo.trf1.jus.br/default.php?p1=200738010058104>. Acesso em: 12 nov. 2011.

BRASIL. Tribunal Regional Federal da 1a Região. Remessa Ex Officio 200533040002898. Tribunal da Sexta Turma. Relator: Desembargador Federal Souza Prudente. 18 fev. 2008. Disponível em: <http://arquivo.trf1.jus.br/default.php?p1=200533040002898>. Acesso em: 12 nov. 2011.

BRASIL. Tribunal Regional Federal da 5ạ Região. Apelação Cível 200780010005109. Tribunal da Terceira Turma. Relator: Desembargador Federal Geraldo Apoliano. 21 maio 2009. D.J.U no 112, p. 438-498, 16 jun. 2009. Disponível em: <http://www.trf5.jus.br>. Acesso em: 12 nov. 2011.

BRASIL. Tribunal Regional Federal da 5a Região. Apelação Cível no 478907/CE 200981000021889. 4a Vara Federal do Ceará. Relator: Desembargador Federal Francisco Barros Dias. 11 maio 2010. ACO/2010.000065 Publicado em 21/05/2010 00:00 (MPUB). 
Disponível em: <http://www.trf5.jus.br/archive/2010/05/

200981000021889_20100520_3228784.pdf>. Acesso em: 10 nov. 2011.

DALLARI, Adilson Abreu. Princípio da Isonomia e Concursos Públicos. Revista Eletrônica de Direito do Estado (REDE), Salvador, n. 6, abr. /jun. 2006. Disponível em:

<http://www.direitodoestado.com/revista/REDE-6-ABRIL-2006-

ADILSON\%20ABREU\%20DALLARI.pdf>. Acesso em: 10 nov. 2011.

DECLARAÇÃO UNIVERSAL DOS DIREITOS HUMANOS. Adotada e proclamada pela resolução 217 A (III) da Assembléia Geral das Nações Unidas em 10 de dezembro de 1948. Disponível em: <http://portal.mj.gov.br/sedh/ct/legis_intern/ddh_bib_inter_universal.htm>. Acesso em: 10 nov. 2011.

INFORMATIVO STF. Brasília: no 636, 15 a 19 de agosto de 2011. Disponível em: <http://www.stf.jus.br/arquivo/informativo/documento/informativo636.htm\#transcricao1>. Acesso em: 17 nov. 2011.

LARENZ, Karl. Metodologia da Ciência do Direito. 3. ed. Lisboa: Fundação Calouste Gulbenkian, 1997.

MACHADO JÚNIOR, Agapito. O controle jurisdicional nos concursos públicos. 2006. 287 p. Dissertação (Mestrado em Direito Público) - Universidade Federal do Ceará, Fortaleza, 2006.

MAIA, Antonio Cavalcanti. As transformações dos sistemas jurídicos contemporâneos: apontamentos acerca do neoconstitucionalismo. 25 jun. 2007. Disponível em: <http://www.mundojuridico.adv.br/cgi-bin/upload/Texto1159(2).pdf>. Acesso em: 10 out. 2011.

MENDES, Gilmar Ferreira. Direitos fundamentais e controle de constitucionalidade. 4. ed. São Paulo: Saraiva, 2004.

MENDONÇA, Paulo Roberto Soares. O raciocínio tópico e a concepção sistemática do direito. Direito, Estado e Sociedade, Rio de Janeiro, v. 13, 1998.

MOTTA, Fabrício. Direitos Fundamentais e Concurso Público. Revista do Tribunal de Contas do Estado de Minas Gerais, Belo Horizonte, v. 28, ed. esp. Disponível em: <http://200.195.70.14/Revista/Content/Upload/Materia/926.pdf>. Acesso em: 10 nov. 2011.

OSÓRIO, Fabio Medina. Os limites da discricionariedade técnica e as provas objetivas nos concursos públicos de ingresso nas carreiras jurídicas. Revista Eletrônica de Direito do Estado (REDE), Salvador, n. 22, abr./jun. 2010. Disponível em:

<http://www.direitodoestado.com/revista/REDE-22-ABRIL-2010-FABIO-OSORIO.pdf>. Acesso em: 10 nov. 2011. 